\section{Complete closure of a colonic bleeding diverticulum using endoclips}

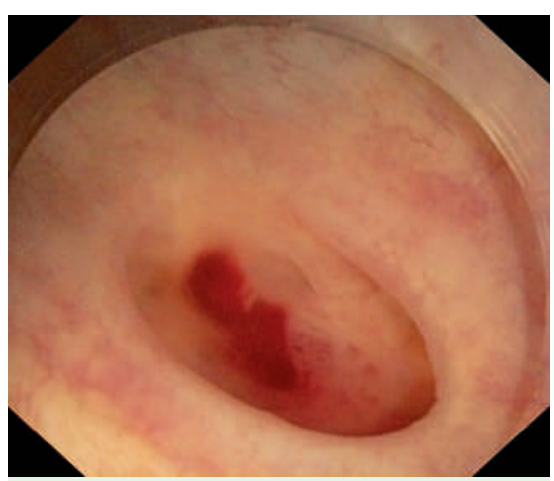

Fig. 1 Active bleeding at the dome of the diverticulum.

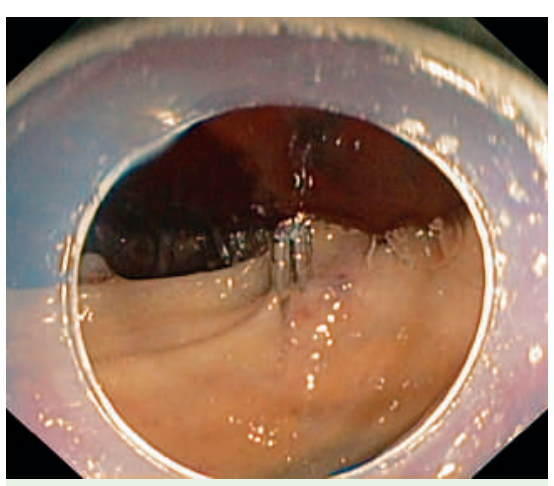

Fig. 2 Complete closure of the lumen of the diverticulum with endoclips.

Epinephrine injection, multipolar heat probe coagulation, and endoclipping at the neck or dome of the diverticulum are the treatments most frequently used for bleeding diverticula $[1,2]$. We obtained hemostasis of a bleeding diverticulum by approximating the margins of the diverticulum.

A 77-year-old man was admitted for painless hematochezia. At admission he had hemoglobin level $8.1 \mathrm{~g} / \mathrm{dL}$ and hematocrit $24 \%$. After bowel preparation an urgent colonoscopy was done using a colonoscope with transparent cap on the tip. A diverticulum oozing blood was seen in the ascending colon ( Fig. 1). After injection of epinephrine, the proximal edge of the diverticulum was moved down using the cap, the mucosa was suctioned, and two endoclips were used to bring together the margins of the diverticulum, obtaining complete closure of the diverticulum and cessation of hemorrhage ( $\bullet$ ig. 2). At 4-months follow-up the patient had experienced no recurrence of bleeding.

This is the first report of closure of an actively bleeding diverticulum by using endoclips to draw its margins together. Endoscopic hemoclipping at the dome of the diverticulum might be at risk of perforation; however the margins of the diverticulum, drawn up with the cap after suction, present a thicker wall for endoclipping. With the present case, we indicate that complete closure of the diverticulum with hemoclips appears to be the safest method for hemostasis of a bleeding diverticulum.

Endoscopy_UCTN_Code_TTT_1AQ_2AZ

\section{P. C. Beretta, C. Cucino}

Endoscopy Unit, Istituto Clinico Santa Rita, Milan, Italy

\section{References}

1 Rino Y, Imada T, Iwasaki $H$ et al. Hemostasis of colonic diverticular bleeding with hemoclips under endoscopic control: report of a case. Hepatogastroenterology 1999; 46: $1733-1735$

2 Bloomfeld RS, Rockey DC, Shetzline MA. Endoscopic therapy of acute diverticular hemorrage. Am J Gastroenterol 2001; 96: 2367-2372

\section{Bibliography}

DOI $10.1055 / s-2007-995330$

Endoscopy 2007; 39: E346

(c) Georg Thieme Verlag KG Stuttgart · New York . ISSN 0013-726X

Corresponding author

\section{Cucino, MD, PhD}

Istituto Clinico Santa Rita

Endoscopy Unit

Via Jommelli 2

20131 Milan

Italy

Fax: +39-02-23934240

claudiacucino@tiscali.it 